\title{
EFEITO DO SILICATO DE CÁLCIO E MAGNÉSIO SOBRE A REPRODUÇÃO DE Meloidogyne javanica E DESENVOLVIMENTO DE MUDAS DE BANANEIRA PRATA-ANÃ ${ }^{1}$
}

\author{
RODRIGO MENDES OLIVEIRA², REGINA CÁSSIA FERREIRA RIBEIRO ${ }^{3}$, \\ ADELICA APARECIDA XAVIER ${ }^{3}$, \\ LÍVIA PIMENTA ${ }^{4}$, GASPAR HENRIQUE KORNDORFER ${ }^{5}$
}

RESUMO- O trabalho teve como objetivo avaliar o efeito de diferentes doses de silicato de cálcio e magnésio sobre a reprodução de Meloidogyne javanica e sobre o desenvolvimento de mudas de bananeira Prata-Anã em solo arenoso. O ensaio foi conduzido em casa de vegetação, em blocos (quatro) ao acaso, em esquema fatorial $5 \times 2$, correspondendo a cinco doses de silicato de cálcio e magnésio $(0 ; 0,64 ; 1,28 ; 1,92$ ou 2,56 g/ $\mathrm{dm}^{3}$ de solo) e duas fontes de variação de $M$. javanica (presença e ausência). As parcelas constaram de três vasos com uma muda de bananeira cada. Nas doses de 1,28 e 2,56 g de silicato de cálcio e magnésio/ $\mathrm{dm}^{3}$ de solo, o número de ovos e o fator de reprodução ( $\mathrm{FR}=$ população final/população inicial) de $M$. javanica foram significativamente menores em relação ao tratamento-testemunha. Porém estas doses de silicato não afetaram o número de galhas e massa de ovos/raiz e número de juvenis de segundo estádio (J2) de $M$. javanica $/ 100 \mathrm{~cm}^{3}$ de solo. Na ausência do nematoide, a dose estimada de $1,61 \mathrm{~g}$ de silicato de cálcio e magnésio/ $\mathrm{dm}^{3}$ proporcionou maior peso de matéria seca do rizoma, porém não afetou a altura de planta, o diâmetro do pseudocaule, o número de folhas e o peso da matéria seca das folhas e da raiz. Maior desenvolvimento das plantas foi obtido naquelas não inoculadas com $M$. javanica. Conclui-se que as mudas tiveram seu desenvolvimento vegetativo afetado pela presença de $M$. javanica e, dependendo da dose do silicato aplicada ao solo, a reprodução do nematoide pode ser afetada, bem como pode proporcionar incremento na matéria seca do rizoma.

Termos para indexação: manejo, silício, nematoide das galhas, Musa.

\section{EFFECT OF CALCIUM AND MAGNESIUM SILICATE ON Meloidogyne javanica REPRODUCTION AND DEVELOPMENT OF BANANA PRATA-ANÃ SEEDLINGS}

\begin{abstract}
The objective of this study was to evaluate the effect of different doses of calcium and magnesium silicate on M. javanica reproduction and the development of banana Prata-Anã seedlings in sandy soil. The assay was carried out in a greenhouse in a randomized block (four) design in factorial $5 \times 2$ corresponding to five levels of silicate $\left(0,0.64,1.28,1.92\right.$ or $2.56, \mathrm{~g} / \mathrm{dm}^{3}$ of soil) and two sources of variation: presence and absence of $M$. javanica. Plots consisted of three pots with one seedling per pot. The doses of 1.28 and $2.56 \mathrm{~g}$ of calcium and magnesium silicate $/ \mathrm{dm}^{3}$ of soil significantly reduced the number of eggs of $M$. javanica and reproduction factor $(\mathrm{RF}=$ final population / initial population) of $M$. javanica compared to control. However these doses of silicate did not affect the number of galls and egg mass/roots and number of second stage juveniles (J2) of M. javanica $/ 100 \mathrm{~cm}^{3}$ of soil. In the absence of the nematode, the estimated dose of $1.61 \mathrm{~g}$ of calcium and magnesium silicate $/ \mathrm{dm}^{3}$ provided higher dry matter of the rhizome, but did not affect plant height, pseudostem diameter, leaf number and weight of the dry matter of leaves and root. Greatest development of the plants was obtained in those ones not inoculated with M. javanica. It was concluded that vegetative development was affected by presence of $M$. javanica and certain doses of silicate applied to the soil can affect the nematode reproduction and increase the rhizome dry matter.
\end{abstract}

Index terms: management, silicon, root-knot nematodes, Musa.

\footnotetext{
'(Trabalho 201-11). Recebido em: 08-08-2011. Aceito para publicação em: 09-05-2012. Parte da dissertação de mestrado em Produção vegetal no semiárido da UNIMONTES do primeiro autor. Apoio Financeiro: FAPEMIG.

${ }^{2}$ Engenheiro Agrônomo. Mestre do curso de Produção Vegetal no Semiárido/UNIMONTES. CEP:39440-000. Janaúba-MG. E-mail: roagronomo@yahoo.com.br

${ }^{3} E^{\circ}{ }^{\circ}$ Agr. Dsc. Profs. Depto. Ciências Agrárias. UNIMONTES. Bolsistas da FAPEMIG. Caixa Postal 91, CEP:39440-000. JanaúbaMG. E-mails: regina.ribeiro@unimontes.br, adelica@unimontes.br

${ }^{4}$ Eng $^{\circ}$ Agr. Dsc., UFU - Campus Umurama, Av. Amazonas, s/nCaixa Postal 593, CEP:38400-902. Uberlândia-MG. E-mail: ghk53@terra.com.br
} 


\section{INTRODUÇÃO}

A bananeira (Musa sp. L.) é uma das principais fruteiras em exploração no Brasil, superada apenas pela cultura da laranjeira. O País destaca-se como o quarto maior produtor mundial de banana, e Minas Gerais como o terceiro maior Estado produtor, com 625.411 .258 toneladas. Dentre as regiões mineiras, o Norte destaca-se como maior produtora (AGRIANUAL, 2010).

Ao longo de suas fases de crescimento e produção, a bananeira e seus frutos são seriamente afetados por problemas fitossanitários, entre os quais se destacam os nematoides. Os danos causados por fitonematoides em cultivos de bananeira são diretamente proporcionais ao aumento de suas populações, ocorrendo redução do tamanho, peso e atraso na maturação dos cachos, pouco perfilhamento e morte das plantas (COSTA et al., 1998, citados por VILAS BOAS et al., 2002). Em levantamento realizado por Neves et al. (2009), em 31 municípios de Minas Gerais e Bahia, de 2003 a 2008, foram detectados em solo e raiz de bananeira os nematoides Meloidogyne spp. Goeldi, Radopholus similis (Cobb) Thorne, Helicotylenchus multicinctus (Cobb) Golden, Pratylenchus coffeae (Zimmermann) Filipjev \& Schuurmans-Stekhoven e Rotylenchulus reniformis Linford \& Oliveira. Os autores constataram ainda que houve aumento na densidade populacional de $\mathrm{Me}$ loidogyne spp. no período avaliado. As estimativas de perdas em Musa spp. causadas por Meloidogyne spp. estão em torno de 8\% (COSTA, 2000). Segundo Cofcewicz et al. (2004), entre as espécies do gênero Meloidogyne, Meloidogyne javanica (Treub) Chitwood e Meloidogyne incognita (Kofoid \& White) Chitwood são as mais frequentes em regiões brasileiras produtoras de banana.

No norte de Minas, os nematoides associados à cultura da bananeira vêm sendo controlados por meio de nematicidas; no entanto, tal estratégia apresenta desvantagens, como prováveis contaminações do ambiente, do aplicador, além de deixarem resíduos nos frutos (VILAS BOAS et al., 2002). Dessa forma, métodos alternativos vêm sendo pesquisados de modo a eliminar ou pelo menos reduzir o uso de produtos químicos.

Entre os elementos minerais utilizados no controle de doenças de plantas, o silício tem proporcionado resultados promissores (DOMICIANO et al., 2010; LIMA et al., 2010). O silício altera o $\mathrm{pH}$ do solo próximo à rizosfera das plantas, influenciando negativamente, dessa forma, na absorção de nutrientes essenciais para ativar mecanismos de defesa, como barreiras estruturais e químicas, como enzimas ligadas à resistência e fitoalexinas (CAI et al., 2008; RODRIGUES et al., 2004). Estudos recentes têm demonstrado que o silício pode estimular o crescimento e a produção vegetal por meio de várias ações indiretas, uma vez que as folhas ficam mais eretas, devido à maior rigidez estrutural dos tecidos. Isto reduz o autossombreamento e protege a planta contra fatores abióticos desfavoráveis, como estresse hídrico, toxidez de alumínio e ferro, entre outros (EPSTEIN, 1994).

O uso de silicato de cálcio e magnésio pode tornar-se uma alternativa interessante no manejo de nematoides na cultura da bananeira, principalmente pela falta de medidas de controle eficazes, economicamente viáveis e sem riscos de toxicidade ao meio ambiente e às pessoas. Dessa forma, os objetivos deste trabalho foram avaliar o efeito de diferentes doses de silicato de cálcio e magnésio sobre a reprodução de $M$. javanica e o desenvolvimento de mudas de bananeira Prata-Anã em casa de vegetação.

\section{MATERIAL E MÉTODOS}

No ensaio, foi utilizado solo de textura arenosa ( $87 \%$ areia, $2 \%$ silte e $11 \%$ argila), com as seguintes características: $0,3 \%$ de matéria orgânica, $2,5 \%$ de umidade residual e $\mathrm{pH} 4,4$, proveniente de Mocambinho-MG. O silicato de cálcio e magnésio (PRNT: 88\%, $\mathrm{SiO}_{2}: 23 \%, \mathrm{CaO}: 38 \%$ ) empregado foi da Recmix ${ }^{\circledR}$ do Brasil . As mudas de bananeiras cv. Prata-Anã foram provenientes do laboratório de cultura de tecidos da UNIMONTES.

Foi utilizada como inóculo de M. javanicauma população pura do nematoide mantida em tomateiros 'Kada', em vasos contendo substrato (solo:areia), previamente tratado com brometo de metila, em casa de vegetação. Os ovos de $M$. javanica foram obtidos a partir de raízes de tomateiros com galhas, conforme a técnica de Hussey \& Barker (1973).

$\mathrm{O}$ ensaio foi conduzido em casa de vegetação, em blocos ao acaso, em esquema fatorial $5 \times 2$, correspondendo a cinco doses de silicato de cálcio e magnésio $\left(0 ; 0,64 ; 1,28 ; 1,92\right.$ ou $2,56 \mathrm{~g} / \mathrm{dm}^{3}$ de solo $)$, que corresponderam a $0 ; 50 ; 100 ; 150$ ou $200 \%$, respectivamente, da recomendação de calagem (ALVAREZ \& RIBEIRO, 1999) e duas fontes de variação: presença e ausência de $M$. javanica. Foram usadas quatro repetições (cada bloco correspondeu a uma repetição), sendo cada parcela constituída por três vasos contendo uma muda de bananeira. Para a montagem do ensaio, o solo foi seco ao ar, peneirado ( $2 \mathrm{~mm}$ de diâmetro) e, em seguida, tratado com brometo de metila $\left(150 \mathrm{~cm}^{3} / \mathrm{m}^{3}\right.$ do substrato por três dias). A seguir, vasos contendo $5 \mathrm{~kg}$ de solo 
foram acrescidos de silicato de cálcio e magnésio conforme o respectivo tratamento, sendo o produto misturado ao solo e incubado por 30 dias com umidade constante $(80 \%$ da capacidade de retenção do solo). Após este período, mudas micropropagadas de bananeira Prata-Anã, aclimatadas por um mês com quatro a cinco folhas, foram transplantadas para os vasos e, um dia após, inoculadas com 3.000 ovos de M. javanica, em quatro orifícios abertos no solo ao redor de cada planta, a uma profundidade de quatro centímetros. Decorridos 30 dias da inoculação, foi realizada adubação com $0,15 \mathrm{~g} / \mathrm{dm}^{3}$ de $\mathrm{P}_{2} \mathrm{O}_{5} ; 0,05 \mathrm{~g} /$ $\mathrm{dm}^{3}$ de $\mathrm{N}$ e $\mathrm{K}_{2} \mathrm{O} ; 0,0003 \mathrm{~g} / \mathrm{dm}^{3}$ de $\mathrm{B}, \mathrm{Zn}$ e Cu, em todos os tratamentos.

As avaliações foram feitas 120 dias após o plantio, sendo a altura da planta avaliada diretamente no local, com fita métrica, medindo-se do solo até a inserção da última folha completamente aberta. $\mathrm{O}$ diâmetro do pseudocaule foi determinado a $15 \mathrm{~cm}$ do solo, com auxílio de um paquímetro. Para quantificar a matéria seca por tratamento, as plantas foram divididas em folha, rizoma e raízes, e levadas à estufa de circulação forçada a $65^{\circ} \mathrm{C}$, até peso constante. Entretanto, para as raízes, foi utilizado um vaso por parcela, e as raízes das plantas dos outros dois vasos foram usadas para avaliação nematológica. Para avaliação dessas variáveis, os sistemas radiculares das plantas foram lavados e, em seguida, pesados e coloridos com floxina B para contagem de galhas e massas de ovos. Logo após, as raízes de cada planta foram trituradas em liquidificador com hipoclorito de sódio a 0,5\% para extração de ovos (HUSSEY; BARKER, 1973), os quais foram posteriormente contados em câmara de Peters em microscópio óptico. O número de juvenis de segundo estádio (J2) foi obtido após o revolvimento do solo de cada vaso para a homogeneização e retirada de uma amostra de $100 \mathrm{~cm}^{3}$, a qual foi submetida a técnica de extração proposta por Jenkins (1964). Em seguida, os J2 foram contados em câmara de Peters, em microscópio óptico. $O$ fator de reprodução (FR) do nematoide foi avaliado pela fórmula $\mathrm{FR}=$ população final (número de ovos/planta + número de J2/vaso)/população inicial (3.000 ovos). Com o FR, calculou-se a supressão do FR (SFR) proporcionada pelas doses de silicato, comparando-se ao tratamento-testemunha (sem silicato).

Os dados obtidos foram submetidos à análise de variância, e as doses foram ajustadas por meio de regressão e/ou pelo teste Scott-Knott a 5\%. As médias das variáveis relacionadas à presença e ausência de M. javanica foram comparadas pelo teste $\mathrm{F}$ a $5 \%$. Para as análises dos dados, foi empregado o programa estatístico SISVAR.

\section{RESULTADOS E DISCUSSÃO}

Não houve interação significativa entre os fatores doses de silicato de cálcio e tratamentos (presença ou ausência de $M$. javanica) nem efeito significativo do fator doses de silicato sobre as variáveis altura, diâmetro, número de folhas, peso da matéria seca das folhas e das raízes de mudas de bananeiras $(P<0,05)$ (dados não apresentados). De acordo com Dutra et al. (2004), as doses de silicato de cálcio de 0,5 e $2 \mathrm{~g} / \mathrm{kg}$ de substrato não aumentaram o desenvolvimento das plantas de feijão comparadas àquelas cultivadas na ausência do silicato. Já a dose de $4 \mathrm{~g} / \mathrm{kg}$ de substrato reduziu significativamente a produção das plantas avaliada por meio do peso da matéria seca da parte aérea, do peso fresco dos grãos e do número de grãos produzidos.

Vários estudos têm demonstrado que a oferta de silício pode influenciar positivamente no crescimento vegetal e na produtividade (SÁVIO et al., 2011). No entanto, de acordo com Epstein (1994), os efeitos benéficos em tais trabalhos geralmente foram expressos de forma mais clara quando as plantas foram submetidas a diferentes condições de estresse a campo. Porém, neste estudo, esse efeito não foi observado, provavelmente porque as plantas não sofreram as condições adversas das condições de campo, como falta de água. Henriet et al. (2006) testaram o efeito de diferentes doses de silício no crescimento de bananeiras em condições de hidroponia e também verificaram que as doses não afetaram o crescimento da planta nem a absorção de água e nutrientes. Da mesma maneira, Korndörfer et al. (2010) não verificaram aumento na produção de matéria seca de Brachiaria decumbens Stapf e Panicum maximum Jack., apesar de ocorrer aumento na concentração de silício nas folhas.

Interação significativa foi observada entre os fatores doses de silicato de cálcio e magnésio e tratamentos (presença ou ausência de $M$. javanica) para a variável matéria seca de rizoma $(P<0,05)$. Na presença de $M$. javanica, nenhum dos modelos testados para dose foi eficiente para explicar a variação dos dados, apresentando não significância $(P>0,05)$ (dados não apresentados). Já, na ausência do nematoide, o peso de matéria seca do rizoma apresentou comportamento quadrático (Figura 1), com ponto de máxima na dose de $1,61 \mathrm{~g} / \mathrm{dm}^{3}$ de silicato de cálcio e magnésio, o que gera um ganho máximo de matéria seca de $9,70 \mathrm{~g} /$ planta. A partir desta dose, houve redução do peso da matéria seca. Lima et al. (2010), ao avaliarem as doses de 0 (testemunha); 56; 112; 168; 224 ou $280 \mathrm{mg} / \mathrm{L}$ de silício, em solução nutritiva para a cultura da soja, obtiveram resultados semelhantes 
para a variável área foliar. Os autores observaram também que, com o aumento das doses de silício, houve decréscimo linear significativo da área foliar de plantas e redução do teor de zinco. Segundo estes mesmos autores, o aumento das doses de silicato de cálcio e magnésio no solo pode ter ocorrido devido ao excesso de calagem e aumento no $\mathrm{pH}$ da solução do solo, o que pode ter levado à indisponibilização de alguns micronutrientes e, consequentemente, à não absorção de alguns nutrientes essenciais. Resultados semelhantes foram observados por Moraes et al. (2009), em trabalhos com feijoeiro. Estes autores verificaram que diferentes doses de silicato de cálcio afetaram a disponibilidade de potássio, cálcio, magnésio, enxofre e zinco. Comparando-se o efeito da presença ou ausência de $M$. javanica dentro de cada dose, verificou-se que, nas doses de 0; 1,92 e 2,56 $\mathrm{g} / \mathrm{dm}^{3}$, não houve diferença significativa da matéria seca de pseudocaule em plantas inoculadas ou não com o nematoide. Já na dose de 0,64 , as plantas infectadas com $M$. javanica apresentaram aumento significativo em relação às plantas não inoculadas com o nematoide, e na dose de 1,28 o peso de matéria seca foi significativamente superior em plantas sem M. javanica (Tabela 1).

De acordo com a análise de variância, verificou-se efeito significativo do fator presença ou ausência de $M$. javanica sobre as variáveis: altura de planta, número de folhas, peso da matéria seca das folhas e do sistema radicular $(P<0,05)$. Maior desenvolvimento das plantas foi obtido em plantas não inoculadas com o nematoide em relação àquelas inoculadas. As demais variáveis agronômicas não foram influenciadas pela presença do nematoide (Tabela 2). Costa et al. (1997), estudando a flutuação populacional de $M$. incognita, em bananal de cv. Nanica, na região de Petrolândia-PE, constataram que níveis populacionais maiores dessa espécie afetavam o desenvolvimento de perfilhos, redução do tamanho, peso, atraso na maturação dos cachos, amarelecimento, declínio e morte das plantas. As plantas sem injúrias podem utilizar nutrientes, água em fotoassimilados em seu pleno desenvolvimento vegetativo, tornando-se mais vigorosas que plantas com alguma infecção causada por patógenos. Os efeitos de nematoides do gênero Meloidogyne spp. sobre o crescimento das plantas normalmente são variados e complexos. De maneira geral, esses efeitos relacionam-se à alteração na absorção e translocação de água e nutrientes, podendo retardar o crescimento de raiz, contribuindo para supressão do desenvolvimento da planta e comprometendo sua produção.

Com relação ao número de ovos de $M$. javanica por sistema radicular e fator de reprodução, foi verificado efeito significativo das doses $(P<0,05)$ (Tabela 3). No entanto, não houve ajuste de modelos de regressão linear e quadrática para ambas as variáveis, assim as médias foram comparadas pelo teste Scott-Knott a 5\%. As doses de 1,28 e 2,56 g de silicato de cálcio e magnésio $/ \mathrm{kg}$ de solo afetaram negativamente a reprodução de $M$. javanica na bananeira, em relação ao tratamento-testemunha (sem silicato). A supressão significativa no FR foi de 63,8\% e 43,5\%, utilizando-se das doses de 1,28 e 2,56 g de silicato/ $\mathrm{dm}^{3}$ de solo, respectivamente, em relação ao tratamento-testemunha (Tabela 3). Resultados semelhantes foram obtidos por Freire (2007) ao trabalhar com diferentes doses de silicato de potássio e silicato de cálcio no controle de $M$. javanica em alface e pepineiros. Dutra et al. (2004) também encontraram redução do número de ovos por raiz de $M$. javanica $\mathrm{e}$ M. incognita, em plantas de feijoeiro, com a aplicação de $4 \mathrm{~g}$ de silicato de cálcio/ $\mathrm{dm}^{3}$ de substrato. Segundo Freire (2007), muito provavelmente, o silício afetou o desenvolvimento pleno das células gigantes de Meloidogyne spp., afetando sua reprodução. Silva et al. (2010) verificaram redução do número de ovos e galhas de $M$. exigua em cafeeiro "Catuai" cultivado em solo corrigido com silicato de cálcio. De acordo com os autores, esta redução na capacidade reprodutiva do nematoide ocorreu devido ao aumento dos derivados da lignina-ácido tioglicólico e das enzimas peroxidase, polifenoloxidase e fenilalaninaamônia-liase. Há evidências de que o envolvimento dos silicatos na indução de resistência pode ocorrer pela participação do próprio silício, fortificando estruturas da parede celular, conferindo aumento da lignificação, dificultando a penetração dos patógenos, ativação de mecanismos específicos como a produção de fitoalexinas e a síntese de proteínas relacionadas à patogênese como quitinases (RODRIGUES et al., 2003; DEEPAK et al., 2008).

Por meio da análise de variância das variáveis: número de galhas e número de massas de ovos por sistema radicular de bananeira, e número de $\mathrm{J} 2$ de M. javanica/100 $\mathrm{cm}^{3}$ de solo, não foram observados efeitos significativos das doses de silicato de cálcio e magnésio. $(P<0,05)$ (Tabela 3). Dutra et al. (2004), ao estudarem o efeito do silicato de cálcio sobre a reprodução de $M$. javanica e $M$. incognita em feijoeiro, também não encontraram diferenças significativas no número de $\mathrm{J} 2$ quando comparadas às doses com o tratamento-testemunha (sem silício). Da mesma forma, Oliveira et al. (2007) não observaram efeito significativo das doses de silicato de cálcio e magnésio para as variáveis número de galhas e massa de ovos de M. javanica em pepineiros, em casa de vegetação. Os 
autores atribuíram estes resultados à pequena quantidade de silício incorporado ao solo. Freire (2007), analisando diferentes doses de silicato de cálcio, silicato de potássio com ou sem fertirrigação de silicato de potássio em alfaces cultivadas a campo, verificou que apenas os tratamentos com aplicação adicional de silício via fertirrigação apresentaram redução do número de galhas de $M$. javanica. De acordo com o mesmo autor, tal fato demonstra a necessidade de reaplicação do elemento no solo ou na planta, devido à perda por lixiviação ou pelo próprio crescimento vegetativo da cultura, demandando maior quantidade de silício disponível.

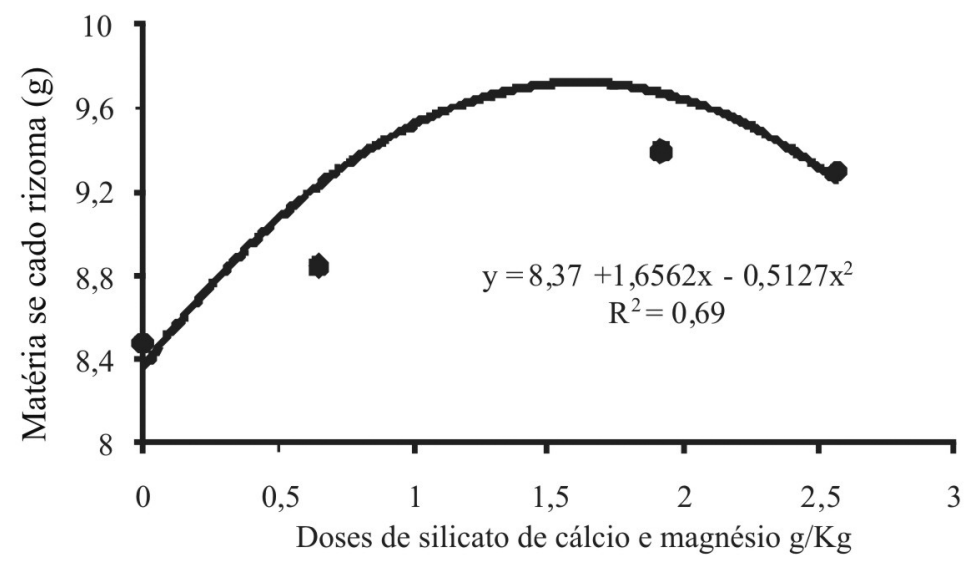

FIGURA 1 - Efeito das doses de silicato de cálcio e magnésio em $\mathrm{g} / \mathrm{dm}^{3}$ de solo sobre a matéria seca do pseudocaule de mudas de bananeiras Prata-Anã não inoculadas com Meloidogyne javanica.

TABELA 1 - Médias do peso da matéria seca de pseudocaule (MSR) de mudas de bananeira Prata-Anã, inoculadas ou não com Meloidogyne javanica $(\mathrm{Mj})$, cultivadas em solo com diferentes doses de silicato de cálcio e magnésio.

\begin{tabular}{crr}
\hline Doses de silicato de cálcio e magnésio & Com Mj & Sem Mj \\
\hline 0,00 & $9,52 \mathrm{a}$ & $8,48 \mathrm{a}$ \\
0,64 & $10,70 \mathrm{a}$ & $8,83 \mathrm{~b}$ \\
1,28 & $8,98 \mathrm{~b}$ & $10,15 \mathrm{a}$ \\
1,92 & $9,38 \mathrm{a}$ & $9,73 \mathrm{a}$ \\
2,56 & $9,61 \mathrm{a}$ & $9,30 \mathrm{a}$ \\
\hline CV $(\%)$ & \multicolumn{3}{c}{7,82} \\
\hline
\end{tabular}

* Médias seguidas pela mesma letra na linha não diferem significativamente entre si, pelo teste $\mathrm{F}$ a $5 \%$.

TABELA 2 - Médias das variáveis agronômicas, altura, diâmetro (D), número de folhas (NF), peso da matéria seca da raiz (MSR), do pseudocaule (MSP) e das folhas (MSF) de mudas de bananeira Prata-Anã, quatro meses após o cultivo com ou sem Meloidogyne javanica (Mj).

\begin{tabular}{ccccccc}
\hline Tratamento & Altura $(\mathrm{cm})$ & $\mathrm{D}(\mathrm{cm})$ & $\mathrm{NF}$ & $\begin{array}{c}\text { MSF } \\
(\mathrm{g})\end{array}$ & $\begin{array}{c}\text { MSP } \\
(\mathrm{g})\end{array}$ & $\begin{array}{c}\text { MSR } \\
(\mathrm{g})\end{array}$ \\
\hline Com $\mathrm{Mj}$ & $20,8 \mathrm{a}$ & $3,1 \mathrm{a}$ & $10,0 \mathrm{a}$ & $18,4 \mathrm{a}$ & $9,2 \mathrm{a}$ & $11,3 \mathrm{a}$ \\
Sem $\mathrm{Mj}$ & $21,9 \mathrm{~b}$ & $3,2 \mathrm{a}$ & $10,5 \mathrm{~b}$ & $19,8 \mathrm{~b}$ & $9,7 \mathrm{a}$ & $14,0 \mathrm{~b}$ \\
\hline $\mathrm{CV}(\%)$ & 4,1 & 5,7 & 5,5 & 6,9 & 7,8 & 29,7 \\
\hline
\end{tabular}

* Médias seguidas pela mesma letra na coluna não diferem significativamente entre si, pelo teste $\mathrm{F}$ a $5 \%$. 
TABELA 3 -Média do fator de reprodução (FR) e do número de ovos, galhas e massas de ovos de Meloidogyne javanica por sistema radicular de bananeira Prata-Anã, quatro meses após o cultivo com diferentes doses de silicato de cálcio e magnésio $\left(\mathrm{g} / \mathrm{dm}^{3}\right.$ de solo).

\begin{tabular}{ccccccc}
\hline Doses & $\mathrm{N}^{\circ}$ ovos & $\mathrm{N}^{\circ} \mathrm{J} 2$ & $\mathrm{FR}^{*}$ & $\begin{array}{c}\mathrm{SFR}^{*} \\
(\%)\end{array}$ & $\mathrm{N}^{\circ}$ galhas & $\mathrm{N}^{\circ}$ massas de ovos \\
\hline 1,28 & $7.343,7 \mathrm{a}$ & $149,5 \mathrm{a}$ & $2,5 \mathrm{a}$ & 63,8 & $258,7 \mathrm{a}$ & $30,2 \mathrm{a}$ \\
2,56 & $11.695,0 \mathrm{a}$ & $125,7 \mathrm{a}$ & $3,9 \mathrm{a}$ & 43,5 & $283,7 \mathrm{a}$ & $37,0 \mathrm{a}$ \\
1,92 & $18.916,0 \mathrm{~b}$ & $112,2 \mathrm{a}$ & $6,3 \mathrm{~b}$ & 8,2 & $227,0 \mathrm{a}$ & $40,7 \mathrm{a}$ \\
0 & $20.435,7 \mathrm{~b}$ & $290,7 \mathrm{a}$ & $6,9 \mathrm{~b}$ & - & $284,2 \mathrm{a}$ & $34,5 \mathrm{a}$ \\
0,64 & $26.002,0 \mathrm{~b}$ & $136,2 \mathrm{a}$ & $8,7 \mathrm{~b}$ & $26,0^{+}$ & $300,0 \mathrm{a}$ & $38,0 \mathrm{a}$ \\
\hline $\mathrm{CV}(\%)$ & 30,5 & 28,0 & 23,8 & & 16,9 & 21,6 \\
\hline
\end{tabular}

Para análise estatística, os dados foram transformados em $\sqrt{x+0,5}$. Letras distintas na coluna representam diferenças significativas ao nível de 5\%, pelo teste Scott-Knott. * FR= população final/população inicial.**Supressão do fator de reprodução.+ Aumento do FR em relação à testemunha.

\section{CONCLUSÕES}

Mudas de bananeira Prata-Anã têm seu desenvolvimento vegetativo afetado na presença de $M$. javanica; no entanto, a aplicação de silicato de cálcio e magnésio ao solo, dependendo da dose, pode afetar a reprodução do nematoide e proporcionar ganho de matéria seca no pseudocaule da planta.

\section{AGRADECIMENTOS}

À Fundação de Amparo à Pesquisa do Estado de Minas Gerais - FAPEMIG, pelo financiamento do projeto e pela concessão da Bolsa de Incentivo à Pesquisa e ao Desenvolvimento Tecnológico - BIPDT .

\section{REFERÊNCIAS}

AGRIANUAL 2010: anuário da agricultura brasileira. São Paulo: FNP Consultoria e Consórcio, 2010. p.195-200.

ALVAREZ, V. V. H.; RIBEIRO, A. C. Calagem. In: COMISSÃO DE FERTILIDADE DO SOLO DO ESTADO DE MINAS GERAIS. Recomendação para o uso de corretivos e fertilizantes em Minas Gerais: 5a Aproximação. Viçosa-MG, 1999. 360 p.

CAI, K.; GAO, D.; LIU, S.; ZENG, R.; YANG, J.; ZHU, X. Physiological and cytological mechanisms of silicon induced resistance in rice against blast disease. Physiologia Plantarum, Lund, v. 134, n. 2, p. 324-333, 2008.
COFCEWICZ, E. T.; CARNEIRO, R. M. D. G.; CASTAGNONE-SERENO, P.; QUÉNEHERVÉ, P. Enzyme phenotype and genetic diversity of root-knot nematodes parasiting Musa in Brazil. Nematology, Leiden, v. 6, n. 1, p. 85-95, 2004.

COSTA, D. da C. Nematoses em banana e abacaxi no Brasil: danos e manejo. In: CONGRESSO BRASILEIRO DE NEMATOLOGIA, 22., 2000, Uberlândia. Anais... p.50-58.

COSTA, D. C. C.; SILVA, S. O.; ALVES, F. R.; SANTOS, A. C. Avaliação de danos e perdas à bananeira cv. Nanica causadas por Meloidogyne incognita na região de Petrolândia-Pernambuco. Nematologia Brasileira, Piracicaba, v. 21, p. 21. 1997.

DEEPAK, S.; MANJUNATH, G.; MANJULA, S.; NIRANJAN-RAJ, S.; GEETHA, N. P.; SHETTY, H. $\mathrm{S}$. Involvement of silicon in pearl millet resistance to downy mildew disease and its interplay with cell wall proline/hidroxyproline-rich glycoproteins. Australasian Plant Pathology, Perth, v. 37, n. 5, 498-504, 2008.

DOMICIANO, G. P.; RODRIGUES, F. A.; VALE, F. X. R.; XAVIER-FILHA, M. S.; MOREIRA, W. R.; ANDRADE, C. C. L.; PEREIRA, S. C. Wheat resistance to spot blotch potentiated by silicon. Journal of Phytopathology, Berlin, v. 158, n. 5, p. 334-343, 2010. 
DUTRA, M. R.; GARCIA, A. I. A.; PAIVA, B. R. T. L.; ROCHA, F. S.; CAMPOS, V. P. Efeito do silício aplicado na semeadura do feijoeiro no controle de nematoides das galhas. Fitopatologia Brasileira, Brasília, v. 29, p. 172, 2004.

EPSTEIN, E. The anomaly of silicon in plant biology. Proceeding of the National Academy Science, Washington, v. 91, n. 1, p. 11-17, 1994.

FREIRE, E. S. Controle dos nematoides das galhas (Meloidogyne spp.) e dos cistos (Heterodera glycines). 2007. 104 f. Dissertação (Mestrado em Fitopatologia) - Universidade Federal de Lavras, Lavras-MG, 2007.

HENRIET, C.; DRAYE, X.; OPPITIZ, I.; SWENNEN, R. Effects, distribution and uptake of silicon in banana (Musa spp.) under controlled conditions. Plant and Soil, London, v.287, p. 359-374, 2006.

HUSSEY, R. S.; BARKER, K. R. A comparison of methods collecting inocula of Meloidogyne spp. including a new technique. Plant Disease Reporter, Washington, v. 57, n. 12, p. 1.025-1.028, 1973.

JENKINS, W. R. A rapid centrifugal-flotation technique for separating nematodes from soil. Plant Disease Reporter, Washington, v. 48, n. 9, p.692. 1964.

KORNDÖRFER, P. H.; SILVA, G. C.; TEIXEIRA, I. R.; SILVA, A. G.; FREITAS, R. S. Efeito da adubação silicatada sobre gramíneas forrageiras e características químicas do solo. Pesquisa Agropecuária Tropical, Goiânia, v. 40, n. 2, p. 119-125, 2010.

LIMA, L. M.; POZZA, E. A.; POZZA, A. A. A.; FONSECA, T. A. P. S.; CARVALHO, J. G. Quantificação da ferrugem asiática e aspectos nutricionais de soja suprida com silício em solução nutritiva. Summa Phtopathologica, Botucatu, v. 36, n. 1, p. 51-56, 2010.

MORAES, S. R. G.; POZZA, E. A.; POZZA, A. A. A.; CARVALHO, J. G., SOUZA, P. E. Nutrição do feijoeiro e intensidade da antracnose em função da aplicação de silício e cobre. Acta Scientiarum Agronomy, Maringá, v. 32, n. 2, p. 283-291, 2009.
NEVES, W. S.; DIAS, M. S. C.; BARBOSA, J. G. Flutuação populacional de nematoides em bananais de Minas Gerais e Bahia (Anos 2003 a 2008). Nematologia Brasileira, Piracicaba, v. 33, n. 4, p. 281-285, 2009.

OLIVEIRA, R. M.; RIBEIRO, R. C. F.; SANTOSNETO, J. A.; XAVIER, A. A.; RIBEIRO, H. R.; OLIVEIRA, R. M. Efeito do silicato de cálcio no controle de Meloidogyne javanica em pepino. In: CONGRESSO BRASILEIRO DE FITOPATOLOGIA, 39., 2007, Maringá. Anais... Maringá: SBF, 2007. p. 296.

RODRIGUES, F. A.; BENHAMOU, N.; DATNOFF, L. E.; BÉLANGER, R. R. Ultrastructural and cytochemical asapects of silicon-mediated rice blast resistance. Phytopathology, St. Paul, v. 93, n. 5, p. 535-546, 2003.

RODRIGUES, F. A.; McNALLY, D. J.; DATNOFF, L. E.; JONES, J. B.; LABBÉ, C.; BENHAMOU, N.; MENZIES, J. G.; BÉLANGER, R. R. Silicon enhances the accumulation of diterpenoid phytoalexins in rice: a potential mechanism for blast resistance. Phytopathology, St. Paul, v. 94, n. 2, p. 177-183, 2004.

SÁVIO, F. L.; SILVA, G. C.; TEIXEIRA, I. R.; BORÉM, A. Produção de biomassa e conteúdo de silício em gramíneas forrageiras sob diferentes fontes de silicato. Semina: Ciências Agrárias, Londrina, v. 32, n. 1, p. 103-110, 2011.

SILVA, R. V.; OLIVEIRA, R. D. L.; NASCIMENTO, K. J. T.; RODRIGUES, F. A. Biochemical responses of coffee resistance against Meloidogyne exigua mediated by silicon. Plant Pathology, Nottingham, v. 59, n. 3, p. 586-593, 2010.

VILAS BOAS, L. C.; TENENTE, R. C. V.; GONZAGA, V.; SILAVA NETO, S. P.; ROCHA, H. S. Reação de clones de bananeira (Musa spp.) ao nematoide Meloidogyne incognita (Kofoid \& White, 1919) Chitwood, 1949, Raça 2. Revista Brasileira de Fruticultura, Jaboticabal, v. 24, n. 2, p. 690-693, 2002. 